\title{
Teaching Family Medicine Residents How to Identify and Address Social Determinants of Health
} Lisa Schoenberger, DO | Rajaa Mourabet, DO | Binju Bose, DO | Qian Gu, DO | Benita Benjamin, DO | Jennifer Saad, DO | Christine Lee, DO | Tara Zahtila, DO

PRiMER. 2021;5:17.

Published: 6/23/2021 | DOI: 10.22454/PRiMER.2021.897179

\section{Abstract}

Introduction: This educational program aimed to teach family medicine residents how to address social determinants of health. The literature reviewed suggested that curricula addressing social needs of patients were sporadic and failed to provide residents with practical ways to apply the knowledge. The program objectives were to provide residents with a thorough understanding of social determinants of health and to provide a practical experience where they could address social needs.

Methods: The program consisted of four didactic sessions in which the residents discussed why addressing social determinants of health is important, designed a screening tool, and were educated on how to assess and communicate with patients. As a longitudinal experience, the residents used the screening tool in their clinic and connected patients with resources. We performed a mixed-methods data analysis to determine if program goals were met.

Results: Survey data showed a statistically significant change in the comfort, understanding, and consistency of addressing social determinants of health. Reflections showed similar results. Residents recognized the importance of being aware of social needs, having conversations with patients about their needs, and considering cost when they implement treatment plans.

Conclusions: Family medicine residents are the future primary care providers for our communities. Therefore, it is important to equip them with the knowledge and ability to address all of the factors affecting their patients' health. Graduates will be able to apply this knowledge to their future patients, and educators can be assured family physicians have the skills to address social determinants of health.

\section{Introduction}

Social determinants of health (SDH) are the conditions in which people are born, live, learn, work, play, and age. Resources that enhance quality of life, such as safe housing, access to education, and availability of healthy foods can have a significant influence on population health outcomes. ${ }^{1}$ Studies suggest that medical care accounts for $10 \%-20 \%$ of the modifiable contributors to health. The other $80 \%-90 \%$ are determined by a person's social determinants of health. ${ }^{2}$

Training programs have begun to address social determinants of health in their curricula, however, the best way 
to approach this topic is undetermined. ${ }^{3}$ Most current strategies aim to increase awareness of the social needs of patients but do not address them in an effective or practical way. ${ }^{3-6}$ Curricula are inconsistent and have insufficient connections to community-based resources. ${ }^{3}$ Currently, inclusion of this material into standard residency training is sporadic and often optional. ${ }^{3}$

We designed a curriculum using cognitive constructivism and behavioral change theory. Cognitive constructivism was implemented by developing critical thinking through reflection. Behavioral change theory was utilized as the learners were given the skills and environment to elicit a changed behavior. ${ }^{7}$ This curriculum was unique because it taught the concepts and improved awareness of SDH and also allowed the trainees to apply their new knowledge by changing their behavior in clinical practice. The goal of this program was to train residents in how to screen for and address the social determinants of health of their patients.

\section{Methods}

\section{Participants and Setting}

The program was instituted at a community hospital family medicine residency program. Thirty residents participated in the program. This program was exempted from formal institutional review board approval by the Feinstein Institutes for Medical Research Northwell Health due to the limited data collected from participants, and because the study design prevented the identity of the subjects from being readily ascertained.

\section{Measures}

We used a mixed-methods approach to evaluate the program. The researchers designed a survey instrument using a 5-point Likert scale to evaluate program success. The survey was based on other surveys used by similar programs aiming to teach SDH to residents. ${ }^{6}$ Several faculty members and residents reviewed and edited the questions to maximize face validity. The Cronbach a was 0.8 , indicating excellent internal consistency in the responses. We analyzed this survey by a quantitative method using a paired $t$ test. The researchers designed a reflective exercise for the study. We analyzed the reflections using grounded theory with a descriptive coding strategy (a qualitative research method). The survey and reflection are available on the STFM Resource Library. ${ }^{8}$ We identified and agreed upon several recurring themes in the reflections.

Both the surveys and reflections were administered on paper. We used an identifying number, known only to the participant, to link pre- and postsurveys and maintain anonymity. We manually transferred the deidentified data to Microsoft Excel.

\section{Procedure}

The first survey was administered before the curriculum was implemented. After 6 months, the follow up survey and reflection were completed. Implementation of this program required four 1-hour didactic sessions.

Residents were able to design a screening tool to meet the needs of their patient population using the Health Leads Screening Toolkit. ${ }^{9}$ Health Leads provides recommended screening and alternative questions. All questions were validated and their precision and reading level were available for reference. During the didactic session, the residents, as a group, discussed and voted on which question to use for each domain. The screening tool they designed is available on the STFM Resource Library. ${ }^{13}$ After participating in the didactic sessions, residents were expected to apply their new knowledge at their ambulatory clinic. SDH screenings were completed for all annual physicals. Residents were expected to address any positive screens, refer the patients to appropriate resources and follow up with each patient, as needed, until the social needs had been sufficiently addressed. 


\section{Results}

Thirty family medicine residents participated in the program and all participants completed the surveys and reflections. We analyzed pre- and postsurvey scores using a paired $t$ test. The $P$ value was $<.05$ for all individual questions and the total scores, which showed a statistically significant change in the residents' level of comfort as well as their understanding and consistency of addressing social determinants of health.

Several themes emerged upon analysis of the residents' reflections. These are shown in Table 4. Twenty-seven out of 30 residents identified a specific plan to address SDH after graduation.

\section{Conclusions}

Prior studies highlighted that most curricula increased awareness but did not address SDH in an effective way. ${ }^{2-4}$ Educational programs lacked practical application ${ }^{4}$ or an association showing physicians increasingly addressed these needs after training ${ }^{5}$. This program was unique in that it taught the content in didactic sessions and also provided the residents with the practical skills required to address these needs with their patients.

The surveys showed a significant improvement in the residents' level of comfort, understanding, and consistency of addressing SDH. The reflections showed an increase in awareness of social needs such as financial strains, ability to access resources and the importance of thorough conversations with patients. Most residents identified a specific plan detailing how they will address the social needs of their patients upon graduation. This extension of knowledge to practice is important, as $80 \%$ of a patient's health depends on their $\mathrm{SDH} .^{1}$

Study limitations included that the program was implemented at one institution with a limited number of residents and all of the data were learner self-reported. Compliance with the screening tool was overseen by faculty. There was no external verification of how often or consistently the screening tool was used and if the needs identified were resolved. Further research could include a retrospective chart review to determine if this curriculum led to increased identification of social needs and how many patients were able to access resources after being identified. We could also follow residents beyond graduation and determine how many graduates address SDH as a standard of care in their practices. We anticipate that further studies that address SDH in residency education can positively impact the health outcomes of patients.

\section{Tables and Figures}

Table 1: Resident Demographics

\begin{tabular}{|l|l|l|l|}
\hline \multicolumn{1}{|c|}{ Postgraduate Year } & \multicolumn{1}{|c|}{ Gender } & \multicolumn{1}{c|}{ Age (Years) } & Race \\
\hline $\begin{array}{l}\text { PGY } 1 \\
10 \text { residents }\end{array}$ & $\begin{array}{l}\text { Female 70\% } \\
\text { Male 30\% }\end{array}$ & $\begin{array}{l}\text { Average age: } 28 \\
\text { Range: 26-30 }\end{array}$ & $\begin{array}{l}\text { Asian } 20 \% \\
\text { South Asian 50\% } \\
\text { White 30\% }\end{array}$ \\
\hline $\begin{array}{l}\text { PGY } 2 \\
10 \text { residents }\end{array}$ & $\begin{array}{l}\text { Female 60\% } \\
\text { Male 40\% }\end{array}$ & $\begin{array}{l}\text { Average age: } 30 \\
\text { Range: 27-34 }\end{array}$ & $\begin{array}{l}\text { Hispanic 10\% } \\
\text { South Asian 50\% } \\
\text { White 40\% }\end{array}$ \\
\hline $\begin{array}{l}\text { PGY } 3 \\
10 \text { residents }\end{array}$ & $\begin{array}{l}\text { Female 80\% } \\
\text { Male 20\% }\end{array}$ & $\begin{array}{l}\text { Average age: } 32 \\
\text { Range: 29-40 }\end{array}$ & $\begin{array}{l}\text { Asian 40\% } \\
\text { South Asian 20\% } \\
\text { White 40\% }\end{array}$ \\
\hline
\end{tabular}


Table 2: Didactic Sessions

\begin{tabular}{|l|l|}
\hline \multicolumn{1}{|c|}{ Session Topic } & \multicolumn{1}{c|}{ Description } \\
\hline Introduction to SDH & $\begin{array}{l}\text { Define SDH } \\
\text { Discuss experiences and challenges }\end{array}$ \\
\hline Design screening tool & $\begin{array}{l}\text { Introduce Health Leads Screening Toolkit9 } \\
\text { Design screening tool }\end{array}$ \\
\hline Conversations with patients & $\begin{array}{l}\text { Review Collaborative Care Method10 } \\
\text { Review BATHE Method }\end{array}$ \\
\hline How to address SDH & $\begin{array}{l}\text { Introduce HITE site } \\
\text { Role play }\end{array}$ \\
\hline
\end{tabular}

Abbreviations: SDH, social determinants of health; BATHE, background, affect, trouble, handling, and empathy; HITE, Health Information Tool for Empowerment.

Table 3: Quantitative Results; Survey Score Means and $P$ Values

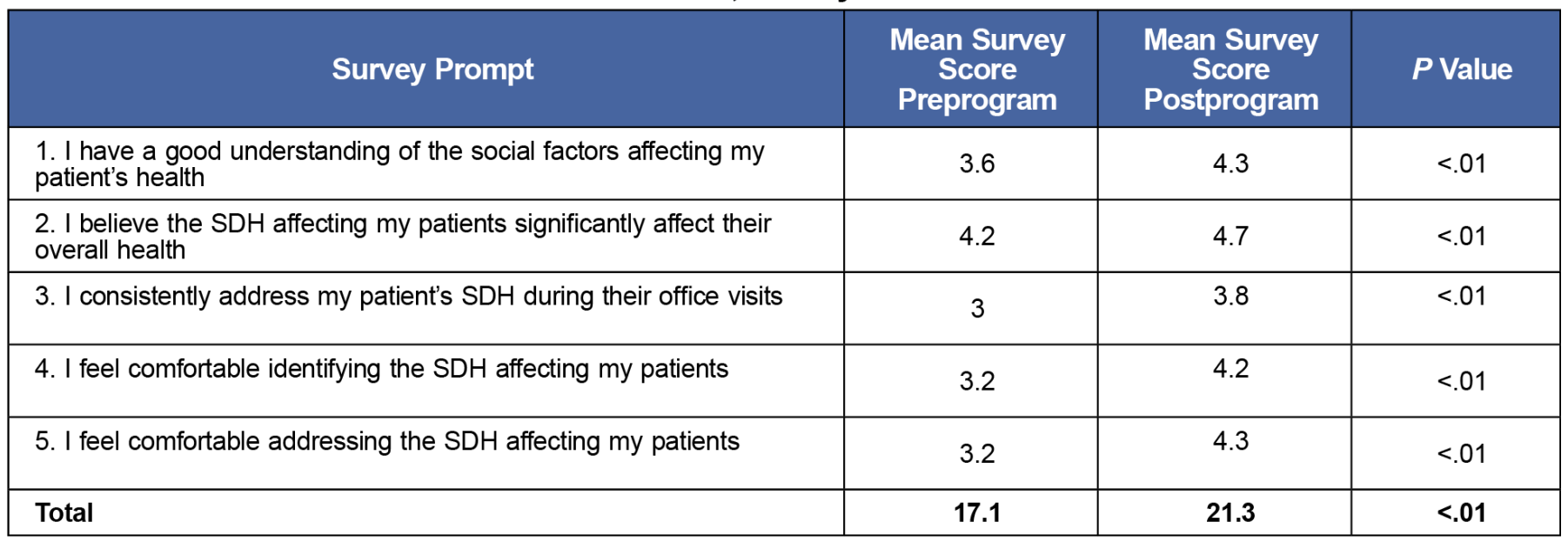

Abbreviation: $\mathrm{SDH}$, social determinants of health.

Table 4: Qualitative Results: Reflection Themes

\begin{tabular}{|l|l|}
\hline \multicolumn{1}{|c|}{ Theme } & \multicolumn{1}{c|}{ Representative Quote } \\
\hline Plans to address SDH upon graduation & $\begin{array}{l}\text { "I plan on taking some time out of annual and new patient visits to } \\
\text { address social factors." }\end{array}$ \\
\hline Increased awareness of social issues & $\begin{array}{l}\text { "This experience helped me to be more cognizant of factors that may be } \\
\text { inhibiting my patients' abilities to receive optimal care." }\end{array}$ \\
$\begin{array}{l}\text { Finances and medication cost were the most common } \\
\text { needs encountered } \\
\text { "I've frequently had to consider the cost of medications and my patients' } \\
\text { ability to pay for them and have found alternatives that were cheaper." } \\
\text { that go beyond medical care }\end{array}$ & $\begin{array}{l}\text { "I now see sometimes patients are afraid to bring it up so starting the } \\
\text { conversation is important." }\end{array}$ \\
\hline $\begin{array}{l}\text { "I think just bringing it up helps patients." } \\
\text { resources }\end{array}$ & $\begin{array}{l}\text { "I am now more aware of resources for me as the physician available to } \\
\text { find out info to help aid my patients with their SDH." }\end{array}$ \\
\hline
\end{tabular}

\section{Corresponding Author}

\section{Lisa Schoenberger, DO}


Northwell Plainview Family Medicine Residency Assistant Professor, Zucker School of Medicine at Hofstra Northwell, 888 Old Country Road, Plainview, NY 11803. 516-719-3096

Lschoenb12@northwell.edu

\section{Author Affiliations}

Lisa Schoenberger, DO - Northwell Plainview Family Medicine Residency, Plainview, NY | and Zucker School of Medicine at Hofstra Northwell, Hempstead, NY

Rajaa Mourabet, DO - Northwell Plainview Family Medicine, Plainview, NY

Binju Bose, DO - Northwell Plainview Family Medicine, Plainview, NY

Qian Gu, DO - Northwell Plainview Family Medicine, Plainview, NY

Benita Benjamin, DO - Northwell Plainview Family Medicine, Plainview, NY

Jennifer Saad, DO - Northwell Plainview Family Medicine, Plainview, NY

Christine Lee, DO - Northwell Plainview Family Medicine, Plainview, NY

Tara Zahtila, DO - Northwell Health Eastern Region | Plainview Hospital | and Zucker School of Medicine at Hofstra/Northwell

\section{References}

1. Social Determinants of Health. Healthcare-Associated Infections. Healthy People 2020.

https://www.healthypeople.gov/2020/topics-objectives/topic/social-determinants-of-health. Accessed December 16, 2018.

2. Magnan S. Social Determinants of Health 101 for Health Care: Five Plus Five. NAM Perspectives. Washington, DC: National Academy of Medicine; October 9, 2017. https://doi.org/10.31478/201710c

3. Siegel J, Coleman DL, James T. Integrating social determinants of health into graduate medical education: a call for action. Acad Med. 2018;93(2):159-162. doi:10.1097/ACM.0000000000002054

4. Sharma M, Pinto AD, Kumagai AK. Teaching social determinants of health: $A$ path to equity or a road to nowhere? [published online ahead of print April 25, 2017]. Acad Med. 2018;93(1):25-30. doi:10.1097/ACM.0000000000001689

5. Schmidt S, Higgins S, George M, Stone A, Bussey-Jones J, Dillard R. An experiential resident module for understanding social determinants of health at an academic safety-net hospital. MedEdPORTAL. 2017;13(1):10647. doi:10.15766/mep_2374-8265.10647

6. Gard LA, Cooper AJ, Youmans Q, et al. Identifying and addressing social determinants of health in outpatient practice: results of a program-wide survey of internal and family medicine residents. BMC Med Educ. 2020;20(1):18. doi:10.1186/s12909-020-1931-1

7. Torre DM, Daley BJ, Sebastian JL, Elnicki DM. Overview of current learning theories for medical educators. Am J Med. 2006;119(10):903-907. doi:10.1016/j.amjmed.2006.06.037

8. Schoenberger L. Wellness Questionnaire. 2020. STFM Resource Library. https://resourcelibrary.stfm.org /viewdocument/wellness-questionnaire?CommunityKey=2751b51d-483f-45e2-81de-4faced0a290a\& tab=librarydocuments. Accessed May 24, 2021.

9. Health Leads Tools. Health Leads. https://healthleadsusa.org/resource-library/health-leads-tools/. Accessed December 16, 2018.

10. Daniel H, Bornstein SS, Kane GC; Health and Public Policy Committee of the American College of Physicians. Addressing Social Determinants to Improve Patient Care and Promote Health Equity: An American College of Physicians Position Paper. Ann Intern Med. 2018;168(8):577-578.

doi:10.7326/M17-2441

11. Lieberman JA III, Stuart MR. The BATHE Method: incorporating counseling and psychotherapy into the everyday management of patients. Prim Care Companion J Clin Psychiatry. 1999;1(2):35-38. 
doi:10.4088/PCC.v01n0202

12. Health Information Tool for Empowerment (HITE). https://hitesite.org/. Accessed December 16, 2018.

13. Schoenberger L. Assessments of Social Determinants of Health Program. 2020. STFM Resource Library. https://resourcelibrary.stfm.org/viewdocument/assessments-of-socialdeterminants?CommunityKey=2751b51d-483f-45e2-81de-4faced0a290a\&tab=librarydocuments . Accessed May 24, 2021.

14. About social determinants of health. World Health Organization. http://www.who.int/social_determinants /sdh_definition/en/. Published September 25, 2017. Accessed December 16, 2018.

15. Artiga S, Hinton E. Beyond Health Care: The Role of Social Determinants in Promoting Health and Health Equity. The Henry J. Kaiser Family Foundation. https://www.kff.org/disparities-policy/issue-brief/beyondhealth-care-the-role-of-social-determinants-in-promoting-health-and-health-equity/. Published May 11, 2018. Accessed December 16, 2018.

16. Social Determinants of Health: Know What Affects Health. Centers for Disease Control and Prevention. https://www.cdc.gov/socialdeterminants/. Published January 29, 2018. Accessed December 16, 2018.

17. NEJM Catalyst Staff. What are the social determinants of health? NEJM Catalyst. https://catalyst.nejm.org/social-determinants-of-health/. Published September 25, 2018. Accessed December 16, 2018.

Copyright $@ 2021$ by the Society of Teachers of Family Medicine 